
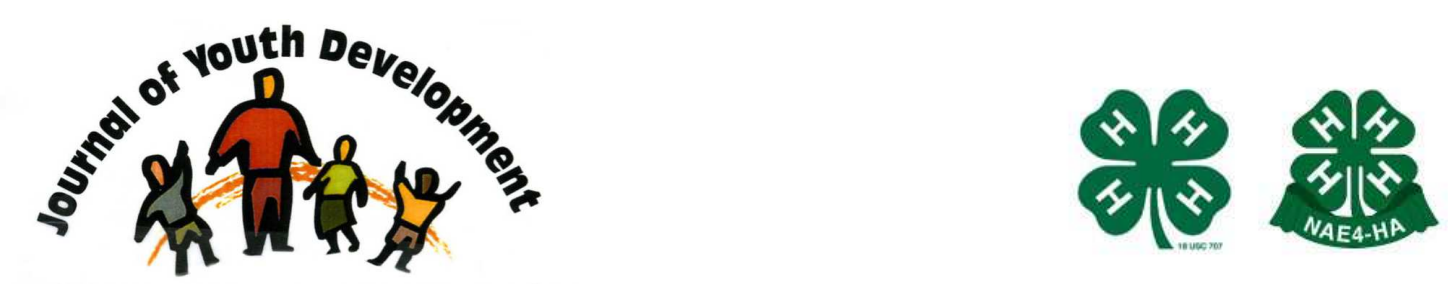

Bridging Research \& Practice

\title{
An Intentional Approach to Achieving Learning Outcomes during a Youth Leadership Residential Program
}

\author{
Jeremy Green \\ 4-H Youth Development \\ Oregon State University \\ Prineville, OR \\ jeremy.green@oregonstate.edu
}

Jamie Davis

4-H Youth Development

Oregon State University

Lakeview, OR

jamie.davis@oregonstate.edu 


\title{
JOURNAL OF YOUTH DEVELOPMENT \\ bridging research and practice



\section{An Intentional Approach to Achieving Learning Outcomes during a Youth Leadership Residential Program}

\author{
Jeremy Green and Jamie Davis \\ Oregon State University
}

\begin{abstract}
The High Desert Leadership Retreat (HDLR) is an annual four-day youth conference which incorporates positive youth development practices to build life skills and increase youth leadership capacity. There are numerous examples in youth development literature of program models and associated outcomes. However, few studies have articulated which aspects of a conference contribute to the achievement of learning outcomes. By utilizing proven program evaluation methods, the achievement of learning outcomes was measured during both formal and informal conference sessions.
\end{abstract}

\section{Introduction}

4- $\mathrm{H}$ youth across the country annually participate in a variety of residential programs including camps, conferences and retreats. Several studies have reported positive impacts of residential programs on youth development (Garst, et al., 2011). Research has also lead to the development of various program models by which youth development professionals can replicate residential programs based upon the type of experience and outcomes they plan to achieve (American Camp Association, 2005). Additionally, numerous evaluation models have been developed to aid planning committees of residential programs in their quest to show positive impact (Garst \& Bruce, 2003).

However, few studies have given aid to program planners by articulating a direct correlation between impacts and an intentional approach to conference planning and design. The authors and their fellow conference planning committee members questioned whether learning outcomes were achieved during intentionally designed formal and informal conference sessions. 


\section{Program Overview}

The High Desert Leadership Retreat (HDLR) is an annual youth conference planned by a diverse group of seven 4-H faculty and staff from the Central Oregon 4-H program area. This four-day conference draws over $1007^{\text {th }}-12^{\text {th }}$ grade youth from six Central Oregon counties. Since the inception of this program, in 1994, over 1700 youth have attended this conference. The primary purpose of the conference is for youth to build leadership and life skills which will enhance their capabilities in school, at home, on the job, and in life. Youth participate in hands-on activities, workshops, seminars, free-choice recreation time and intentionally-designed living arrangements.

The event is held over a three day weekend; youth participants arrive on a Friday evening and depart Monday afternoon. Throughout the weekend, youth participants participate in formal learning through leadership workshops and seminars. The workshops and seminars are tailored to meet the learning needs of both younger youth (grades 7-9) and older youth (grades 10-12) and include some workshops and large group sessions for all participants.

Lodging takes place in resort condominiums and youth are arranged based on gender and age. Youth are separated in groups of 6-8 and are assigned a screened and trained 4- $\mathrm{H}$ volunteer as their chaperone for the duration of the weekend. These groups of youth are housed for the weekend in independent living situations which creates an ideal environment for informal learning. Each group is provided with a budgeted amount of money and as a cohesive group is responsible for developing their own menu for the weekend, by which they then create a shopping list and purchase the food at a local grocery store. Additionally youth are charged with dividing the cooking responsibilities, including meal preparation and clean up. The chaperone is there to provide oversight and ensure that a cooperative and safe environment is maintained.

The conference planning committee intentionally integrates time for youth to make their own decisions. Activities include recreation (swimming, basketball, tennis and racket ball etc.) group games or simply peer group "hang out" time. Youth have the opportunity to practice sound decision making during time designed to let youth be youth.

\section{Purpose of Evaluation}

Research findings outline how 4-H residential experiences positively affect the life skills and leadership capacities in youth (Garton, Miltenberger, \& Pruett, 2007). Additionally, the Targeted Life Skills model (Hendricks, 1998) and the Presentation of Essential Elements of Youth Development by Cathann Kress (2004) have served as guiding principles for HDLR planning committees for the past several years. Previous conference evaluations have confirmed positive impacts in the areas of youth development education, life skills and leadership capacity.

In 2011 the HDLR planning committee sought to improve the delivery method of the conference with the intention of creating even greater impact. Therefore the planning committee adopted a new conference schedule and delivery method with the intent to strengthen both the formal and informal learning environments and opportunities during the conference. The purpose of this study was to conduct a qualitative evaluation measuring the achievement of learning outcomes during formal and informal conference sessions. 


\section{Steps for Replication}

The following steps can be taken by planning committees of residential programs to replicate this evaluation:

1) Create a logic model for the event (clearly articulate learning outcomes for the event)

2) Break down the event into categories including: formal and informal learning opportunities

3) Precisely map out how each learning opportunity can be linked to learning outcomes

4) Create an inclusive event schedule including ample time for both formal and informal learning opportunities

5) Develop a conference evaluation which measures intended outcomes of both formal and informal learning

\section{Evaluation Methods}

The evaluation process was two-fold. To evaluate formal learning, at the close of each workshop and seminar, youth were presented with a voluntary and anonymous written survey. Youth, who chose to participate in this evaluation, were prompted to respond to two questions, "What was the most important leadership skill you learned in this class?" and "How do you plan to use this skill in the next year?" Workshop presenters distributed and collected the written surveys at the conclusion of each session.

And secondly, condo living groups were brought together at the conclusion of the weekend to evaluate informal sessions. Each group was given flip chart paper and prompted to discuss, "What were the most important things you learned by living in the condo with your peer groups?" The discussion groups were moderated by one trained facilitator. Small groups discussed their thoughts and recorded them on flip chart paper.

Data analysis was performed by using a systematic text analysis of the individual written surveys and the small group flip chart notes. The text of each was separately grouped into major themes. Major themes were then sub-divided into minor-themes. Major themes were categorized by having appeared in both the written evaluations and the discussion group notes. Minor themes were derived from having only appeared in one of the two evaluative steps.

Through the process of triangulation, the data was verified. Three facilitators independently grouped and identified major and minor themes. Only major themes identified by all three facilitators are reported in this article. Additionally, all other 4- $\mathrm{H}$ faculty and staff involved with HDLR, but not involved with the study, performed an audit of the data analysis process and results.

\section{Findings}

Four major themes emerged through the evaluation process including: collaboration, communication, decision making, and understanding self. Results indicated that learning outcomes were achieved during both formal and informal learning sessions. A snap shot of the four major themes highlights these results.

Of the four major themes, collaboration was the most prevalent. Through the focus groups, participants reflected that the conference "condo life" provides opportunity through 
collaboration to overcome differences in meeting expectations set by their peers and chaperones to complete household tasks and achieve respect of their roommates. Additionally, youth indicated that collaboration skills learned in the condo life directly impacted their relationships and approach to group work during formal learning sessions.

Participants identified communication as a major skill strengthened throughout the weekend. Multiple seminars including, public speaking, parliamentary procedures, low ropes and mock court focused on effective communication. Discussion group data illustrated an increase in understanding the importance of listening and how that skill is integral to effective communication. It is also worth noting that participants' documented effective communication as a highly important component of "condo life".

Decision making was often linked to classes taught around goal setting and how to process and make appropriate teen choices. Equally important, was how small group discussion participants reported use of these learned skills to their interactions during informal events of the evenings and through interactions with peers in the condos.

Self awareness was derived from youth reflections on how they gained personal perspective about their own strengths and weaknesses, about how a positive attitude greatly impacts their enjoyment level of different life experiences, and how having a better understanding of themselves enhances their understanding of others. Self awareness was an unintentionallyderived outcome of the formal learning sessions and therefore a future topic for formal learning sessions.

\section{Limitations}

Certain limitations apply to the findings. Despite the large number of active participants in the study (96\% participation rate), end of session qualitative written surveys, to evaluate formal learning, were entirely voluntary. Caution should be taken when generalizing the results to all conference participants. Additionally, discussion groups to evaluate informal learning were established by the youth grouped together by condo, which was determined by age. Therefore due to the age span of conference participants $\left(7^{\text {th }}-12^{\text {th }}\right.$ grade) discussion group findings may be more representative of either younger youth $\left(7^{\text {th }}-9^{\text {th }}\right)$ or older youth $\left(10^{\text {th }}-12^{\text {th }}\right)$. In the future, separate evaluations should be directed to the differing age groups. Finally, the results could be impacted by answers and observations of youth whom have attended the conference over multiple years.

\section{Conclusion}

The results of this evaluation confirm the importance of approaching conference planning from a holistic standpoint. Residential programs including youth camps, conferences and retreats provide formal learning opportunities where youth can directly apply learned skills to the informal learning environments of the event. This enhances the opportunity for positive youth development to occur. An intentional approach to planning should be taken when considering each aspect of a conference, including workshops/seminars, free choice time, and living arrangements in order to better provide a cohesive learning environment and maximize achievement of learning outcomes. 


\section{References}

American Camp Association. (2005). Directions: Youth Development Outcomes of the Camp Experience. October 23, 2011, from: www.acacamps.org/research/enhance/directions.php

Garst, B.A., \& Bruce, F.A. (2003). Identifying 4-H camping outcomes using a standardized evaluation process across multiple 4-H educational centers. Journal of Extension [On-line], 41(3). Article No. 3RIB2. Available at: www.joe.org/joe/2003june/rb2.shtml.

Garst, B., Nichols, A., Martz, J., NcNeely, N.N., Bovitz, L.,Frebertshauser, D., et al. (2011). Examining Youth Camping Outcomes Across Multiple States: The National 4-H Camping Research Consortium (NCRC). Journal of Youth Development [On-Line], Volume 6, No. 1. Article No. 110601FA001. Available at: http://data.memberclicks.com/site/nae4a/JYDfinal 110601x.pdf

Garton, M.S., Miltenberger, M., \& Pruett, B. (2007). Does 4-H camp influence life skill and leadership development? Journal of Extension [On-line], 45(4). Article No. 4FEA4. Available at: www.joe.org/joe/2007august/a4.shtml

Hendricks, P. (1998). Targeting life skills model. Iowa State University Extension. Retrieved October 15, 2011, from www.extension.iastate.edu/4H/lifeskills/

Kress, C. (2004). Essential elements of 4-H youth development. National 4-H Headquarters, CSREES USDA. Accessed October 21, 2011, from www.national4hheadquarters.gov/library/Essential Elements Satellite.ppt

National 4-H Headquarters. (1999). Essential Elements Overview.

Retrieved October 21, 2011, from: http://4htools.cals.arizona.edu/cssSite/essentialElements.cfm

(C) Copyright of Journal of Youth Development Bridging Research and Practice. Content may not be copied or emailed to multiple sites or posted to a listserv without copyright holder's express written permission. However, users may print, download or email articles for individual use. 